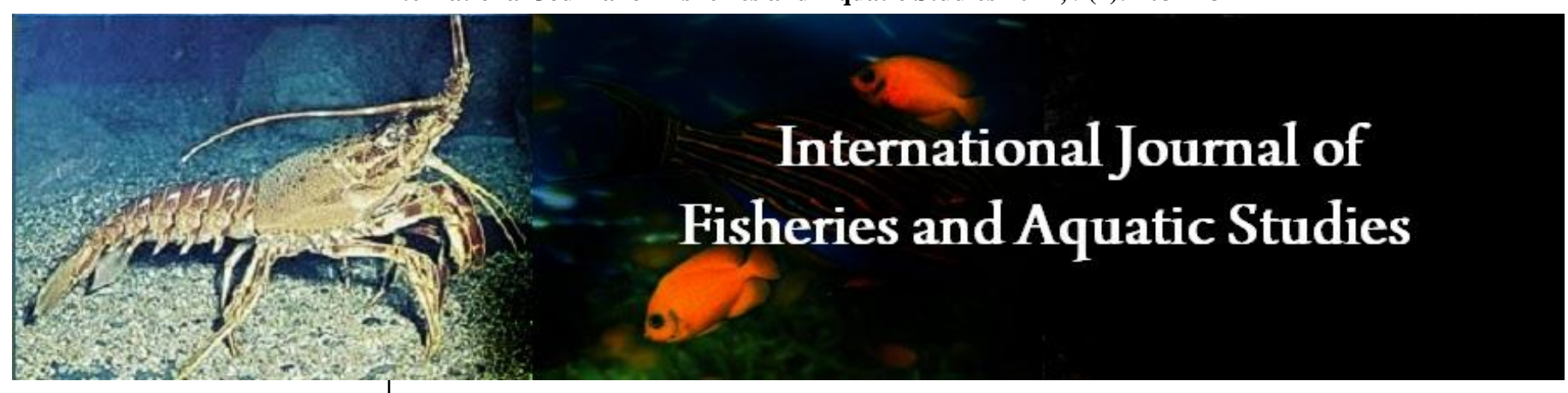

E-ISSN: 2347-5129

P-ISSN: 2394-0506

(ICV-Poland) Impact Value: 5.62

(GIF) Impact Factor: 0.549

IJFAS 2021; 9(1): 403-413

(C) 2021 IJFAS

www.fisheriesjournal.com

Received: 08-11-2020

Accepted: 19-12-2020

Jean Baptiste Kassi

PhD in Costal and Marine

Environment, Lecturer at

University Center for Research

and Application of Remote

Sensing, Abidjan, Ivory Coast,

University FHB Cocody, Ivory

Coast, Côte d'Ivoire

Gnahoua Yannick Koko

PhD Student in Marine Science,

at University Center for

Research and Application of

Remote Sensing, Abidjan, Ivory

Coast, Côte d'Ivoire

Brice Abaka Mobio

$\mathrm{PhD}$ in Costal and Marine

Environment, Lecturer at

University Center for Research

and Application of Remote

Sensing, Abidjan, Ivory Coast,

University FHB Cocody, Ivory

Coast, Côte d'Ivoire
Corresponding Author:

Jean Baptiste Kassi

$\mathrm{PhD}$ in Costal and Marine

Environment, Lecturer at

University Center for Research

and Application of Remote

Sensing, Abidjan, Ivory Coast,

University FHB Cocody, Ivory

Coast

\section{Contribution of remote sensing to the characterization of oceanic variables and their influences on the distribution of tunas in Ivorian waters from 2013 to 2018}

\author{
Jean Baptiste Kassi, Gnahoua Yannick Koko and Brice Abaka Mobio
}

DOI: $\underline{\text { https://doi.org/10.22271/fish.2021.v9.i1e.2427 }}$

\begin{abstract}
In view of the threat posed by overfishing of tuna in Gulf of Guinea, the present study was initiated in order to contribute to the sustainable management of this endangered fish species. This study is based on the analysis of oceanic parameters and their influences on the availability of tunas in Côte d'Ivoire. For this purpose, remote sensing data from MODIS, SMOS and ERA Interim sensors were used to estimate Chlorophyll-a concentration, temperature, sea surface salinity, Upwelling Index and turbulence. In addition, the tuna stock data from the Aquaculture and Fisheries Direction of Côte d'Ivoire. An analysis of the oceanic parameters as a function of the tuna stocks allowed to understand the relationships between these parameters and the availability of tunas in Ivorian waters and offshore. The results show that sea surface temperature and Chlorophyll-a concentration are the most preponderant parameters in the distribution of tunas. Preferred spawning periods for tuna cover from December to June with areas of low turbulence, salinity between ( 34 and $35 \mathrm{psu}$ ) and temperatures above $26^{\circ} \mathrm{C}$ between latitudes $0^{\circ}$ and $3^{\circ} \mathrm{N}$.
\end{abstract}

Keywords: Remote sensing, temperature, upwelling, chlorophyll-a, salinity, turbulence

\section{Introduction}

The coastal regions of the Gulf of Guinea (GG) constitute one of the main marine ecosystems for the production of living marine resources for the populations of West Africa. (Sherman et al., 1991) ${ }^{[1]}$. Côte d'Ivoire, a coastal country belonging to the Gulf of Guinea, benefits effectively from this ecosystem by developing several activities, one of the most important of which is fishing. Tuna fishing constitutes the nerve center of the Ivorian fishing industry.

Since the 1980s, the Ivorian continental shelf has been subject to strong anthropogenic pressures, urbanization, wastewater discharge, and other localized pollution, habitat degradation, unsustainable fishing practices, and global climate change. These situations have put fish stocks under threat of overfishing (Binet, 1982) [2]; (Chika et al., 2006) [3]. Understanding recruitment mechanisms in marine fish populations is a major challenge in fisheries research. The importance of oceanic processes has become increasingly apparent in determining recruitment levels (Bakun and Parrish, 1982) ${ }^{[4]}$; (Bakun et al., 1991) ${ }^{[5]}$. However, it is the recent advancement of remote-sensing technology, providing biological and physical observations with sufficient spatial and temporal resolution, which has permitted us to verify fish recruitment mechanisms, as well as to explore operational metrics for ecosystem-based assessment and management frameworks for the resource concerned (Plattet al., 2003) ${ }^{[6]}$; (Platt and Sathyendranath, $2006{ }^{[7]}$. In fact, overfishing poses a threat to this fishery resource and is gradually leading to a deficit of this resource in the Ivorian marine environment.

Several programs and projects have been initiated with aview to better managing and monitoring natural resources. It is in this perspective that this study was initiated in order to understand the influence of oceanic parameters on the distribution of pelagic species. The Ivorian coastline is part of the large marine ecosystem of the Gulf of Guinea Current (GG) which runs from Guinea Bissau to Angola (Fig.1). This coastline located in West Africa, represents only part of the Gulf of Guinea (GG) precisely in the Central West African Upwelling Region (CWAU). It is bounded by the Cape of Palms (border with Liberia) to the west, and the Cape of Three Points (in Ghana) to the east. 
The Ivorian seaboard extends over 566 kilometers with a variable width of less than 5 kilometers on the crystalline and metamorphic basement in the western part to nearly 50 kilometers to the east on the clayey sands and sandstones of the continental terminal. (Anoh et al., 2008) ${ }^{[8]}$.

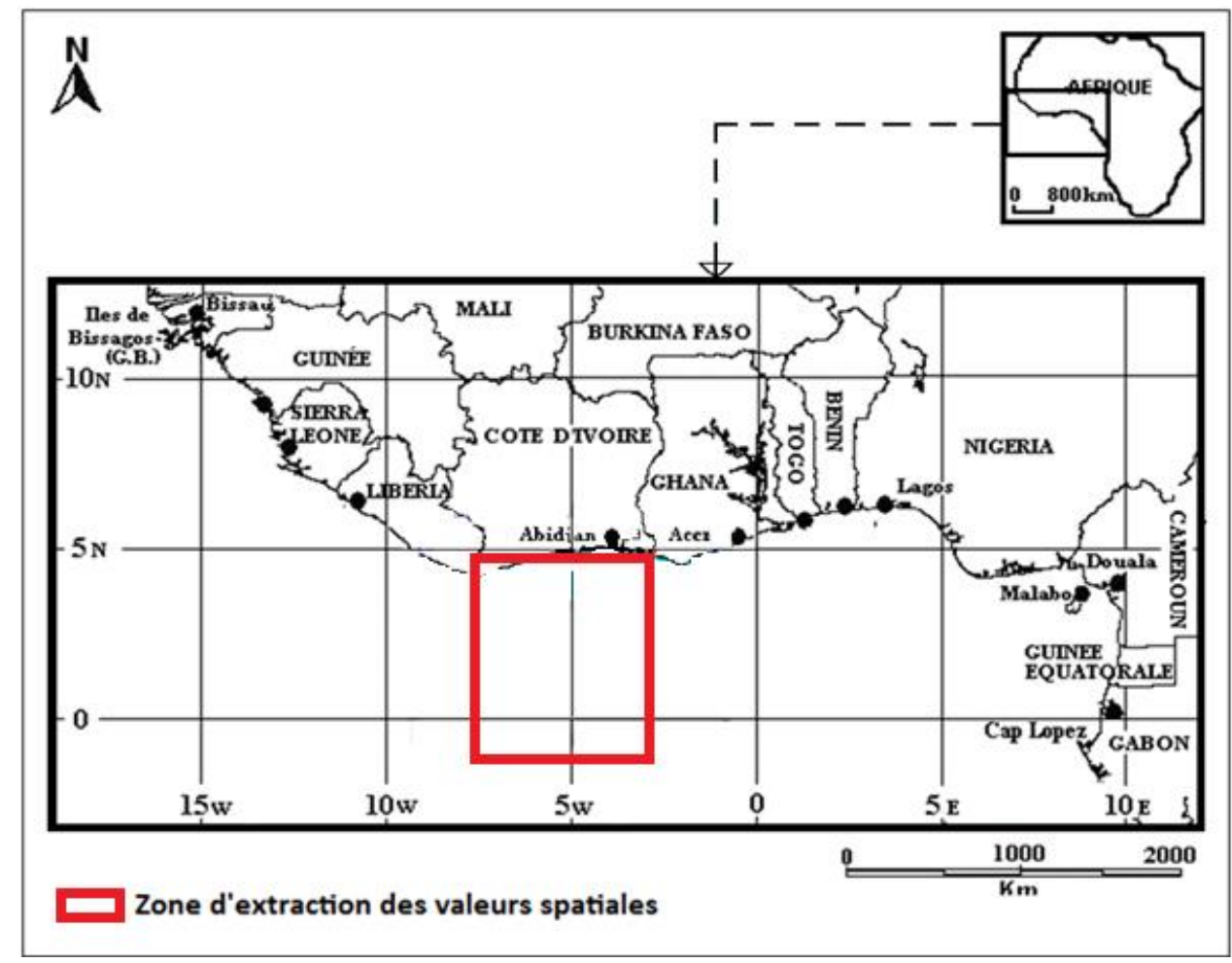

Fig 1: Location of study area in relation to the Gulf of Guinea

\section{Materials and methods}

\subsection{Data used}

The variables mapped in this study i.e. surface temperature, chlorophyll_a concentration, water column mixing index (turbulence), Upwelling index and sea surface salinity can be characterized by a range of remote sensing sensors. In this study, data from the European Space Agency's SMOS (Soil Moisture and Ocean Salinity) sensor and MODIS_Aqua data were used. The SMOS sensor will indeed allow the measurement of sea surface salinity (SSS). The MODIS sensor will be used to measure the color of the ocean and therefore to accurately estimate the concentration of chlorophyll-a in Ivorian marine waters and the sea surface temperature while allowing to observe cold upwelling. Wind data (Interim ERA) is a set of data that will be important to characterize the Upwelling phenomenon. The fishery statistics data from Aquaculture and Fisheries Direction will allow a comparative analysis to be made between the results of the oceanic variables and the actual tuna catches.

\subsection{Methodology}

\subsubsection{Estimation of chlorophyll concentration}

Chlorophyll-a concentration images were processed using SeaDas software to produce monthly and annual mean maps. The processing of these images was done in three main steps: The combination of the images in order to group them together to obtain a set of data, the extraction of the study area and finally the realization of the monthly and annual average maps.

\subsubsection{Estimation of surface temperature}

In order to estimate the variability of coastal upwelling, the sea surface temperature (SST) produced from the MODIS sensor images was used. These SST images were processed using SeaDas software to produce monthly and annual average maps. The processing of these images was done in three main steps: Combining the images into a dataset, extracting study area and finally the realization of the monthly and annual average maps.

\subsubsection{Estimation of the upwelling index}

This calculated upwelling index is based on Ekman's theory of mass transport related to wind stress. (Bakun et al., 1973)

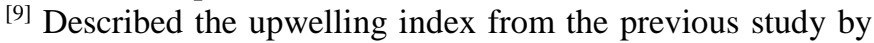
(Ekman et al., 1905) ${ }^{[10]}$. This index evaluates the volume of upwelling flows. To do this, the meridian (v) and the zonal components $(\mathrm{u})$ of the winds are calculated (By Interim ERA) using equations (1) and (2): as follows

$$
u=\frac{R \cdot T}{\mathrm{~Pa}} * \frac{\Delta \mathrm{Py}}{\mathrm{L} \cdot \mathrm{f}} \text { (1) et } v=\frac{R \cdot T}{\mathrm{~Pa}} * \frac{\Delta \mathrm{Px}}{\mathrm{L} \cdot \mathrm{f}}
$$

Where $R$ is the ideal gas constant $(R=258 \mathrm{j}$. Kg-1 K-1), $\mathrm{T}$ is standard room temperature $(\mathrm{T}=288 \mathrm{~K})$,

$\mathrm{Pa}$ is standard atmospheric pressure $(\mathrm{pa}=1013.5 \mathrm{hPa})$, $\Delta \mathrm{px}$ et $\Delta \mathrm{py}$ are the zonal and meridional pressure differences (hPa),

$\mathrm{L}(\mathrm{km})$ is the distance between the locations used to calculate the gradient pressure and $\mathrm{f}$ is the Coriolis parameter defined as twice the vertical component of the Earth's angular velocity. $(\Omega)$ The local vertical where $f=2 \Omega \sin (\theta)$ at the latitude $\theta$. This transport depends on latitude and wind stress. The upwelling index summarizes the oceanic surface water flows per $\mathrm{km}$ of coastline. (m3s-1 km-1), in the direction Qx (West-East) and the direction of Qy (North-south) is expressed according to the following equations (3) and (4): 


$$
Q_{X}=\frac{\tau_{y}}{\text { f. } \rho} * 10^{3} \text { (3) } \quad Q_{y}=\frac{-\tau_{x}}{\text { f. } \rho} * 10^{3}
$$

The Ivorian coast has a West-East orientation. The East-West (Qx) direction equation will be used for this study.

Thus Ty and TX, which are the wind stress factors, are estimated from the wind speed according to equations (5) and (6):

$$
\tau_{y=\rho_{\mathrm{a}} \cdot C d \cdot \sqrt{u^{2}+v^{2}} \cdot v}(\mathbf{5}) \quad \tau_{x=\rho_{\mathrm{a}} \cdot C d \cdot \sqrt{u^{2}+v^{2}} \cdot u}
$$

Where: $\rho=1.2 \mathrm{~kg} \mathrm{~m}-3$ (air density)

$\mathrm{Cd}=1.4 \cdot 10-3$ empirical resistance coefficient)

$\mathrm{U}$ and $\mathrm{V}$ are wind components in $\mathrm{m} \cdot \mathrm{s}-1$.

Given the Coriolis factor (9.94 Ggg10-5 s-1 à $\left.43^{\circ} \mathrm{N}\right)$, $\rho$ a and $\rho$ the air and sea densities, respectively, Cd the drag coefficient, $\mathrm{U}$ and $\mathrm{V}$ the wind speed components. The Ivorian coast has a West-East orientation. The west-east direction equation $\mathrm{T}$ will therefore be used in this study

\subsubsection{Estimation of the turbulence index}

The energy transmitted in the water column by the wind creates turbulence in the superficial layers of the sea (Kassi,
2012) ${ }^{[10]}$. Therefore, the wind mixing index in the surface layer is usually calculated by the cube of the wind speed according to the (Bakun et al., 1973) ${ }^{[11]}$.

\subsubsection{Estimation of sea surface salinity}

Monthly averages of salinity images measured at the marine surface of the Gulf of Côte d'Ivoire over six years were calculated and used to establish the time series for the temporal analysis of the interannual and seasonal variability of the parameter studied. Monthly and annual mean values were used to establish monthly and annual distribution maps of sea surface salinity

\section{Results and Discussion}

3.1 Seasonal and interannual variability of biophysical parameters

\subsubsection{The concentration of chlorophyll}

Regarding seasonal variability, the highest values of Chlorophyll concentration were observed all along the coast from March to November and below $0^{\circ}$ Latitude in June (Fig. 2). As for the interannual variation in the concentration of Chlorophyll_a there is a general decrease in the concentration of Chlorophyll from the coast to the open sea except in 2016 (Fig. 3).

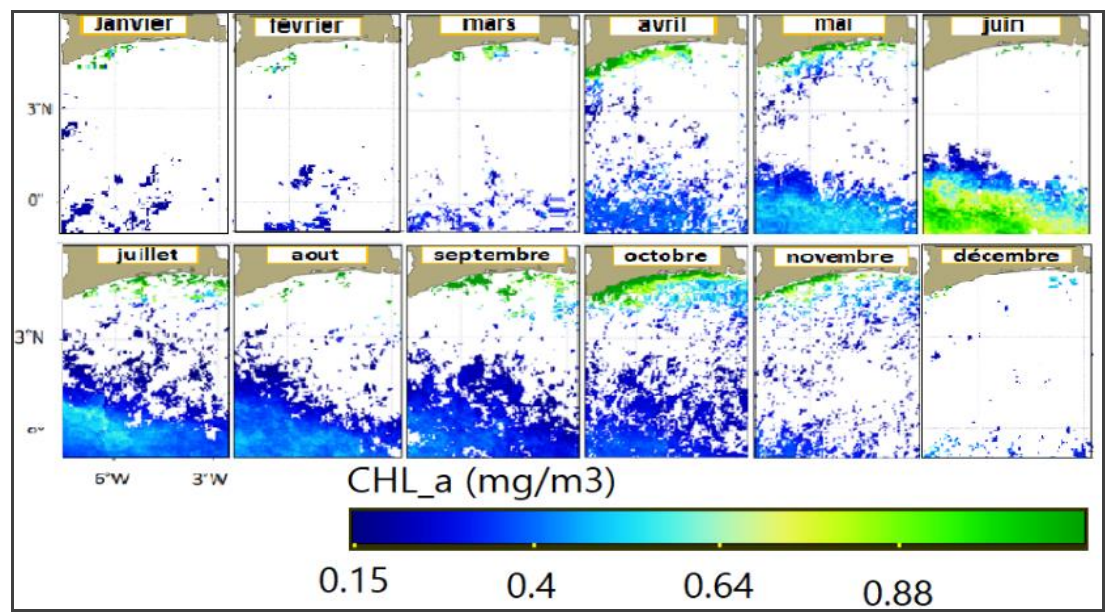

Fig 2: Monthly Averages of Chlorophyll_a Concentration from 2013 to 2018

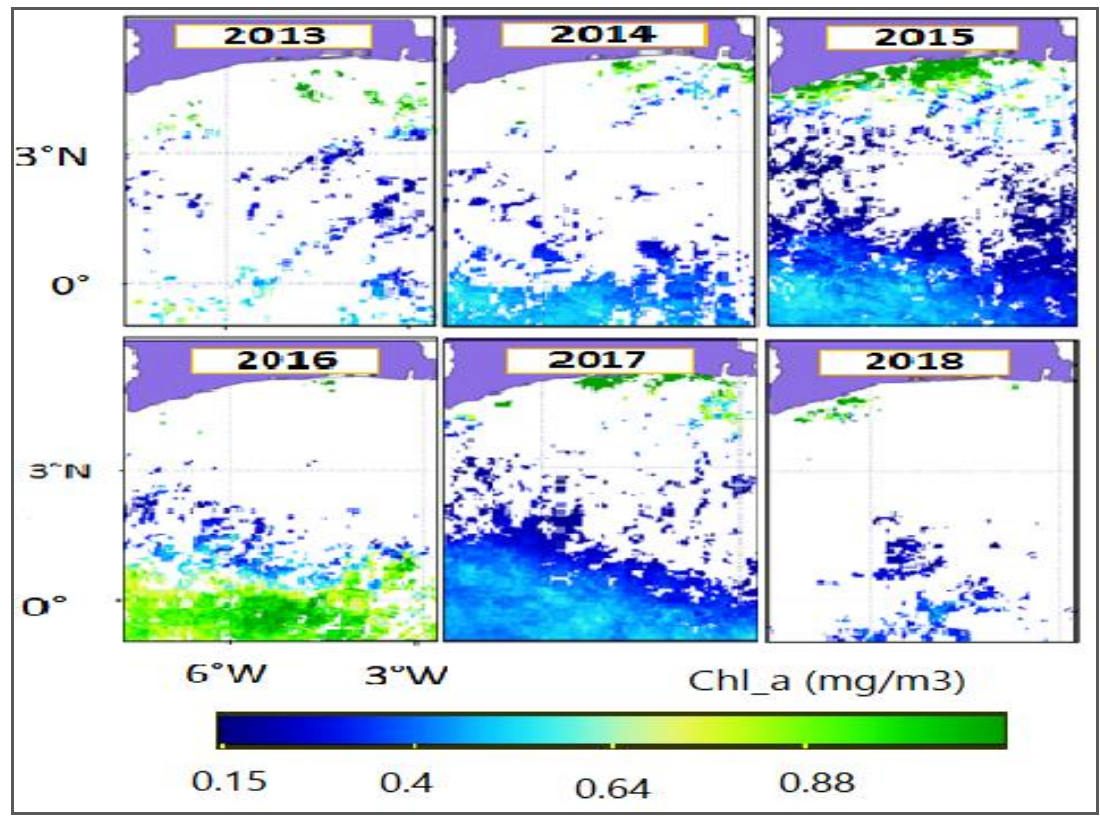

Fig 3: Annual variation of Chlorophyll a Concentration 
Figure 4 shows the seasonal variation in Chlorophyll_a over the six-year study period. The high values of Chlorophyll_a are observed during the Great Cold Season (GCS).

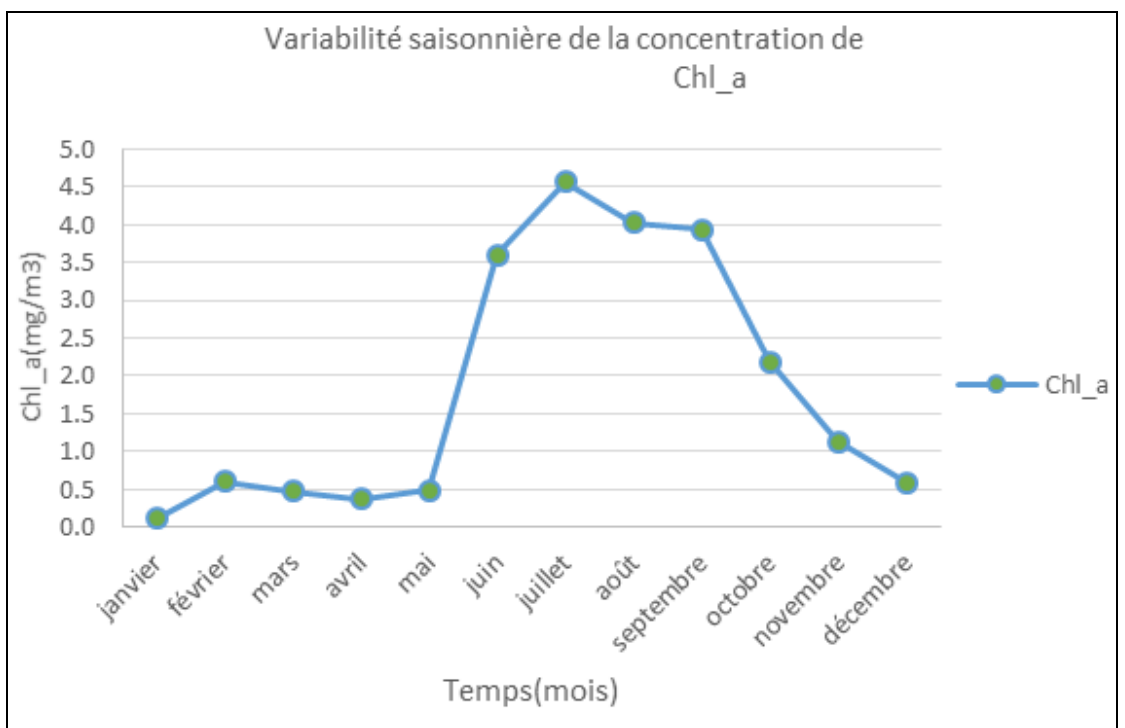

Fig 4: Seasonal Variation of Chlorophyll Concentration from 2013

\subsubsection{Sea surface temperature}

Figure 5 shows the seasonal variation in sea surface temperature. Indeed, the maximum values are in the months of March to May and November to December with a peak of $29.3^{\circ} \mathrm{C}$ in April. The lowest SST value was observed in
August $\left(25.4^{\circ} \mathrm{C}\right)$ during the great cold season. Figure 6 shows the interannual variability of sea surface temperature over the period 2013-2018. The variation is almost identical over the entire study period. The highest SST values are found between latitudes 4 and $2^{\circ} \mathrm{N}$.

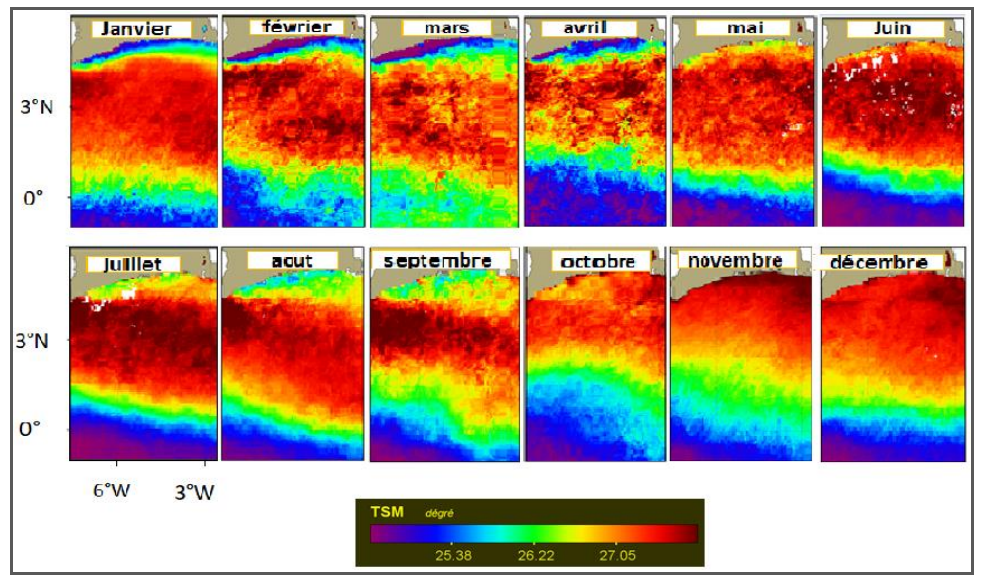

Fig 5: Monthly averages of Sea Surface Temperature from 2013 to 2018

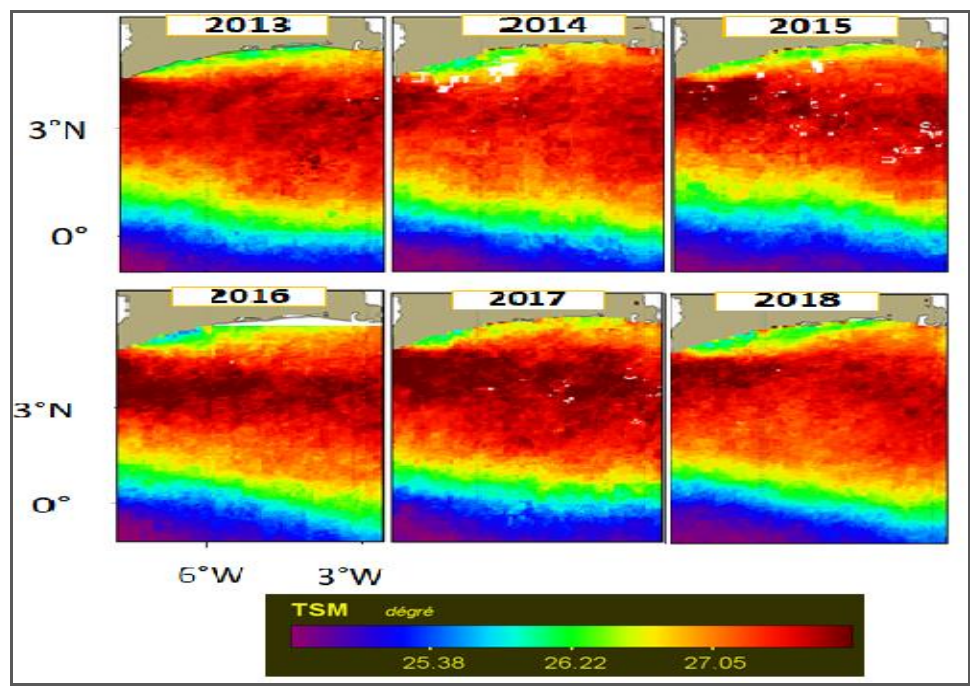

Fig 6: Annual variation of Sea Surface Temperature 
Figure 7 shows the variation in SSTs over the study period. The SST value increases from 27.5 to $29.3^{\circ} \mathrm{C}$ from January to April and then gradually decreases from June to August to reach the minimum value of $25.4^{\circ} \mathrm{C}$. The SST increases again from September to December where a value of $28.7^{\circ} \mathrm{C}$ was recorded. The cold water invades the entire coast of Côte d'Ivoire during the great cold season with an average temperature of $25.9^{\circ} \mathrm{C}$.

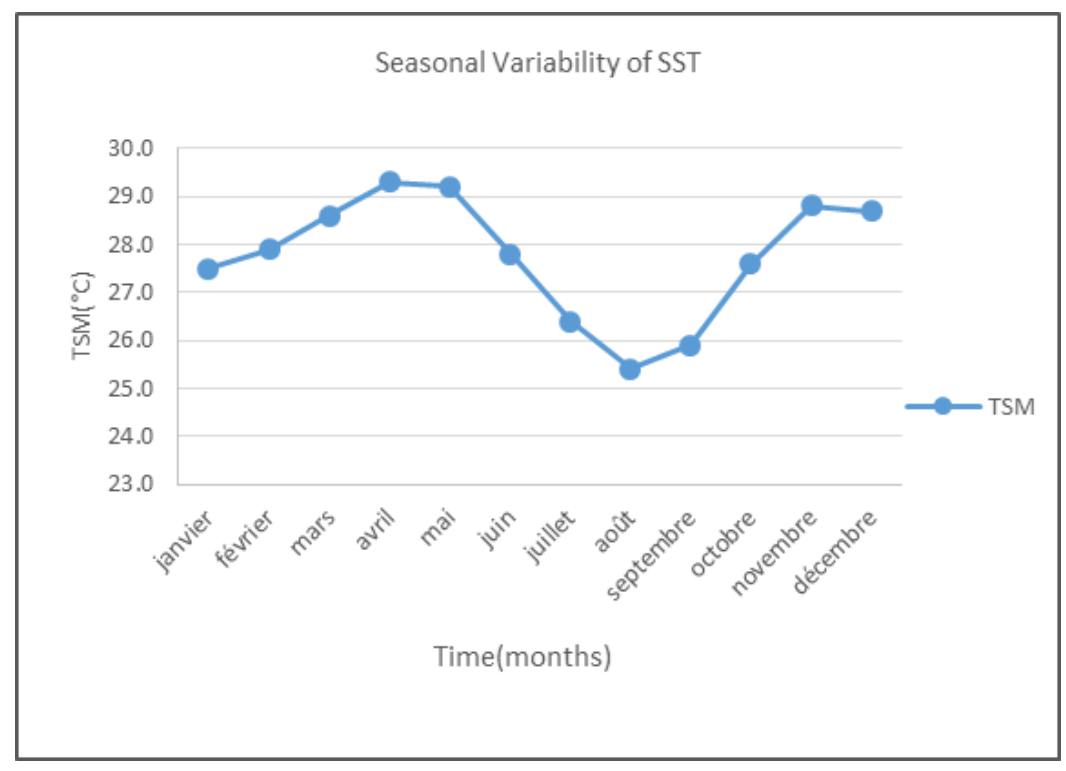

Fig 7: seasonal variation of Sea Surface Temperature from 2013 to 2018

\subsubsection{Seawater turbulence}

The analysis of Figure 8 gives us a general knowledge of the stability of the Ivorian water column from 2013 to 2018. There is an alternation of low and high turbulence values in the study area. The high values indicate the presence of turbulent waters that negatively influence the recruitment of pelagic species. Figure 9 shows the changes in the water column stability index for each year of the study period. The low values of turbulence are between latitudes $2^{\circ} \mathrm{N}$ and $3^{\circ} \mathrm{N}$ over the entire study period. The value of turbulence becomes important from $0^{\circ}$ and around $1^{\circ} \mathrm{S}$ of latitude.

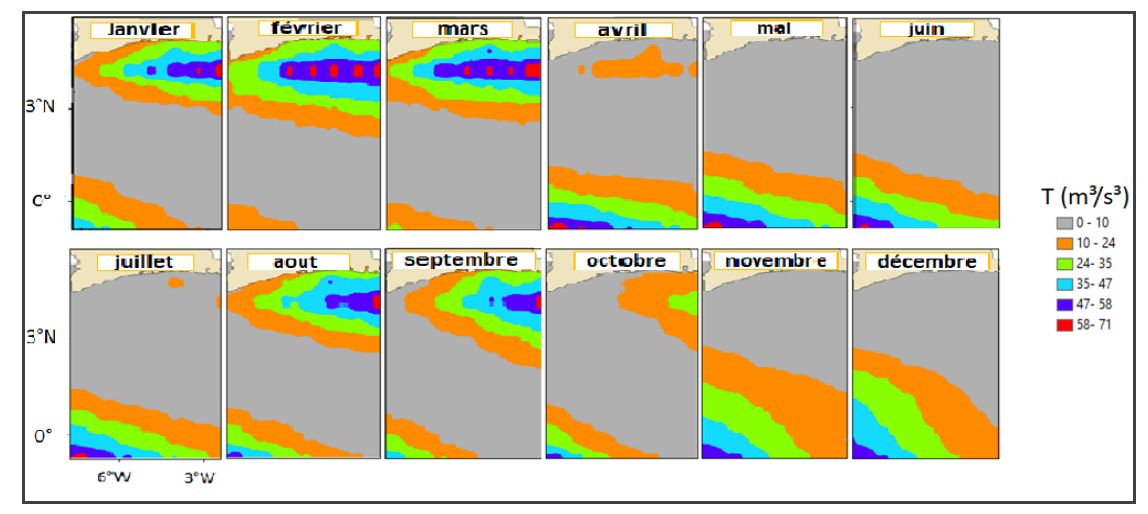

Fig 8: Monthly averages of Sea Turbulence from 2013 to 2018

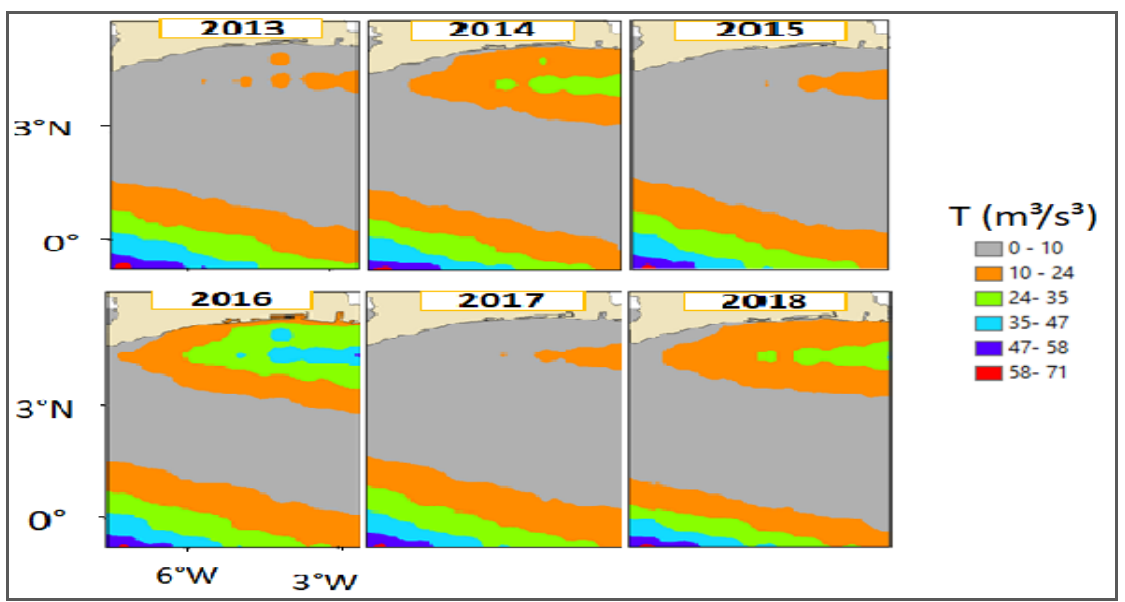

Fig 9: Annual Variation in Sea Turbulence 
Figure 10 shows the seasonal variations in sea turbulence over the six-year study period. The global analysis of this figure shows an increase in the turbulence values from January to May with a maximum value of $11.8 \mathrm{~m}^{3} / \mathrm{s}^{3}$. A decrease in turbulence was then observed from June to October. From October to November, the turbulence increases again to reach $5.3 \mathrm{~m}^{3} / \mathrm{s}^{3}$ before dropping to $3.2 \mathrm{~m}^{3} / \mathrm{s}^{3}$ in December.

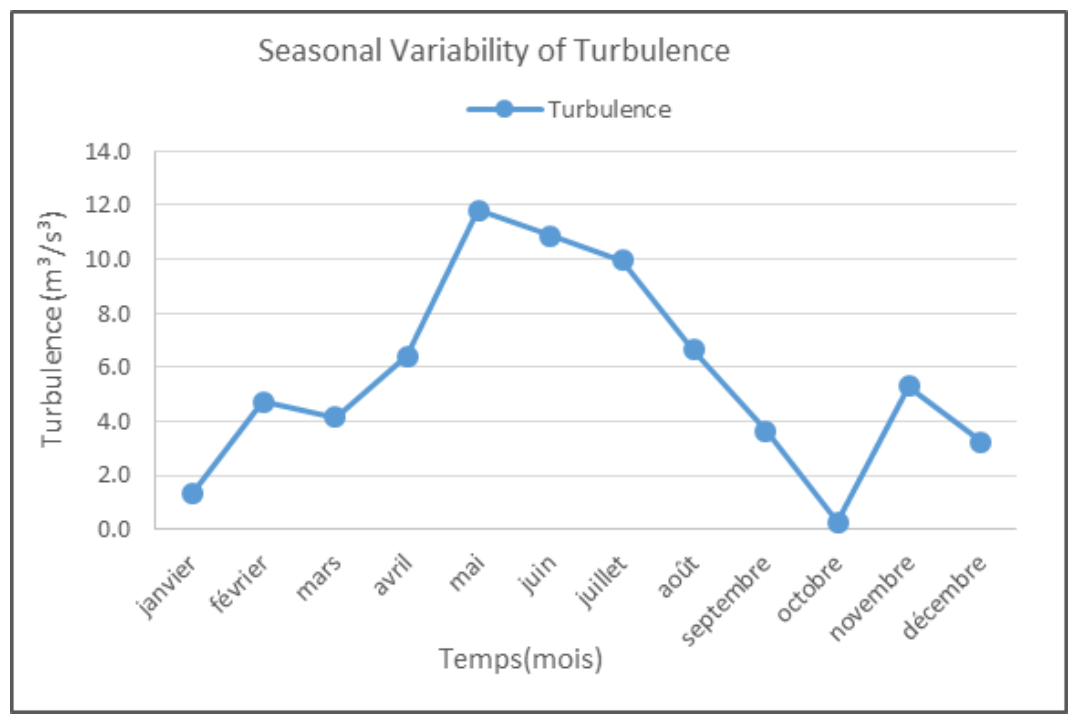

Fig 10: seasonal variation of sea turbulence from 2013 to 2018

\subsubsection{Seasonal Variability of the Upwelling Index}

Figure 11 shows the monthly change in the Upwelling Index over the six-year study period (2013-2018). The lowest values of the index were observed during the period of NovemberJanuary and also in the month of May with values dropping up to $700 \mathrm{~m}^{3} / \mathrm{s} / \mathrm{km}$ at the coast. The annual variations in the
Upwelling Index for Ivorian waters and offshore are shown in Figure 12. In general, we note that the values of the Upwelling Index increase between 2013 and 2017 progressively from the coast to the open sea over the entire study period. The high values of the index occur in 2014 and 2015 while the low values are between 2013 and 2017.

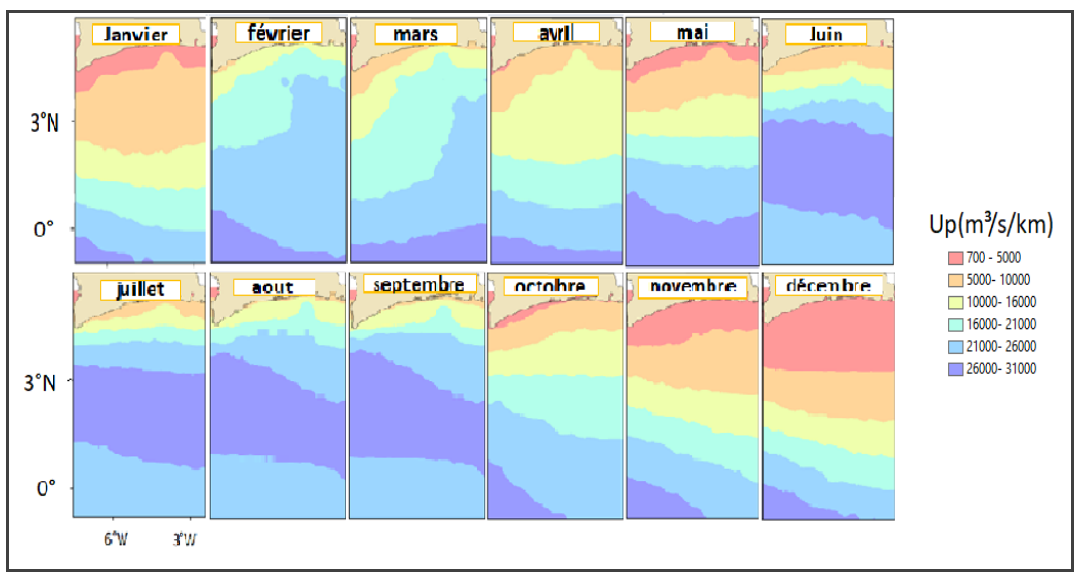

Fig 11: Monthly averages of the Upwelling Index from 2013 to 2018

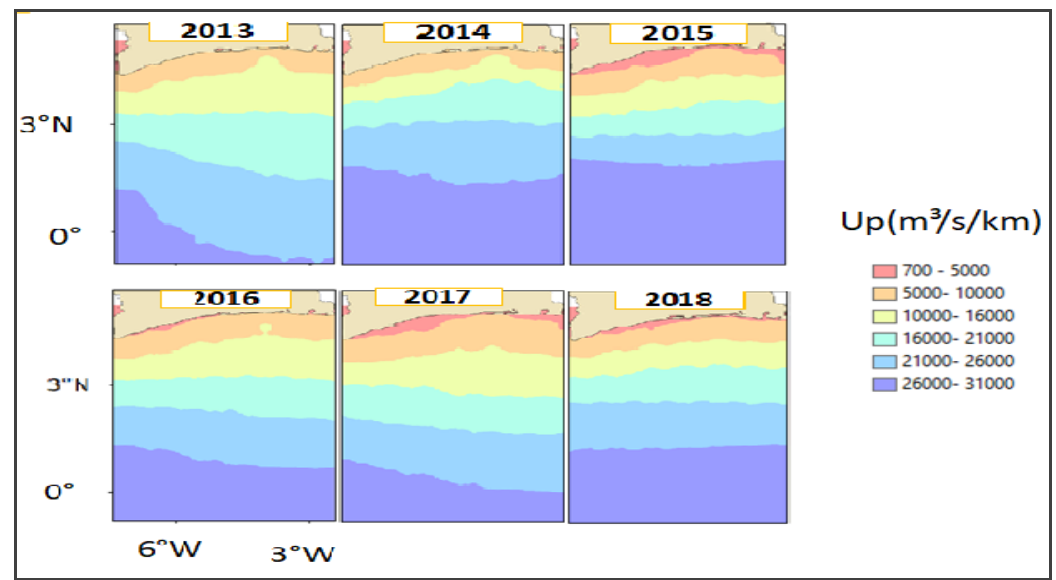

Fig 12: Annual variation of the upwelling index 
In Ivorian marine waters and offshore, the upwelling index follows the same variations as seawater turbulence (Fig. 13).
The highest values of the upwelling index are observed during the great cold season (July to September).

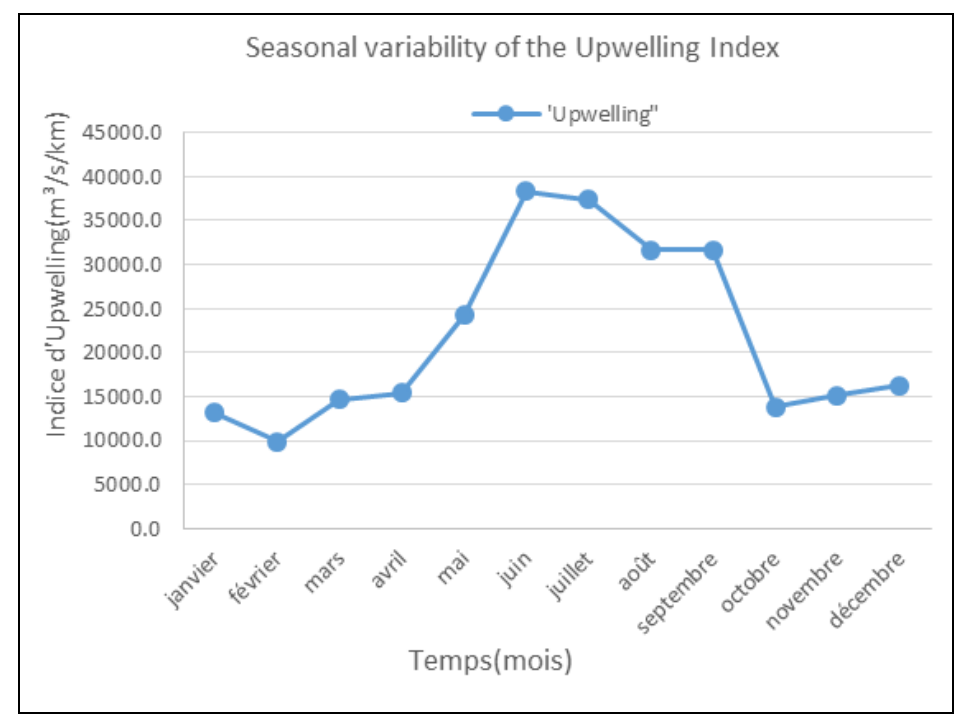

Fig 13: seasonal variation of the upwelling index from 2013 to 2018

\subsection{Seasonal and Interannual Variability in Sea Surface}

\section{Salinity}

Analysis of seasonal variability shows low salinity at the coast, which increases as one moves offshore (Fig. 14). The period from December to March is marked by average salinity (34-35psu) over the entire coastline. From June onwards, more or less important MSS values are noted in Ivorian waters and offshore with an average around 36 psu. The GSF shows a high salinity during the year in the study area. Figure 15 shows the interannual variations in sea surface salinity from 2013 to 2018 . Here, salinity values increase as you go out to sea. They are relatively between 34 and 35 psu.

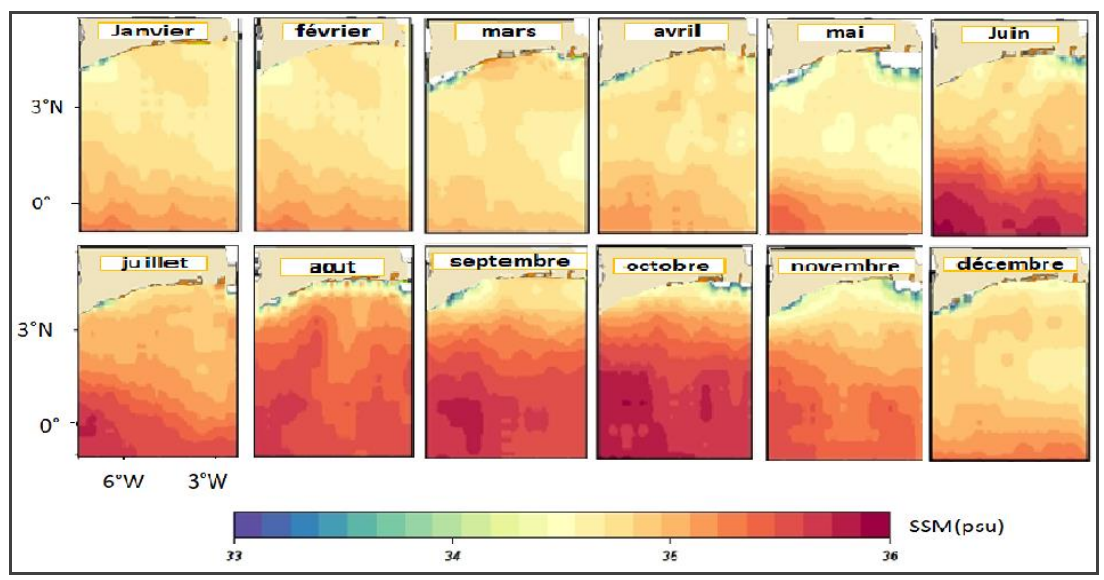

Fig 14: Monthly Averages of Sea Surface Salinity from 2013 to 2018

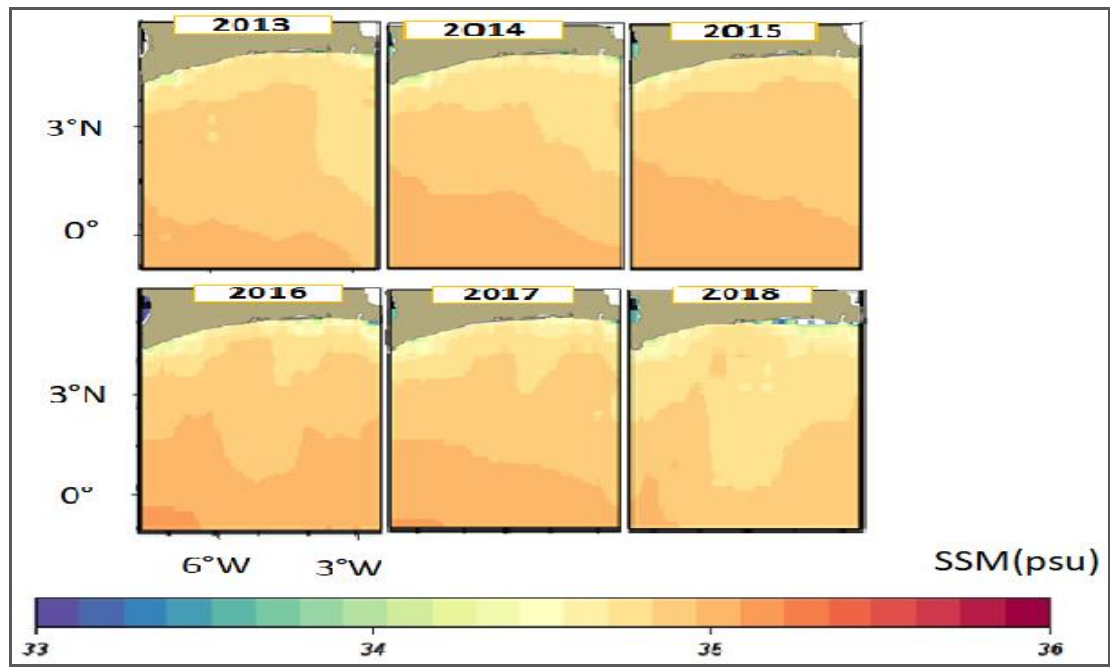

Fig 15: Annual variation in SSS 
Figure 16 shows the monthly variation in sea surface salinity. We observe an increase in MSS from January to February before experiencing a decrease from March to May to reach a value of 33.9 psu. We then see a growth in SSS from June to
July before dropping in August. The peak of MSS is observed in September during the GSF with the value of 35.3 psu. The last quarter shows a decrease in the SSM to reach the value of 33.8 psu.

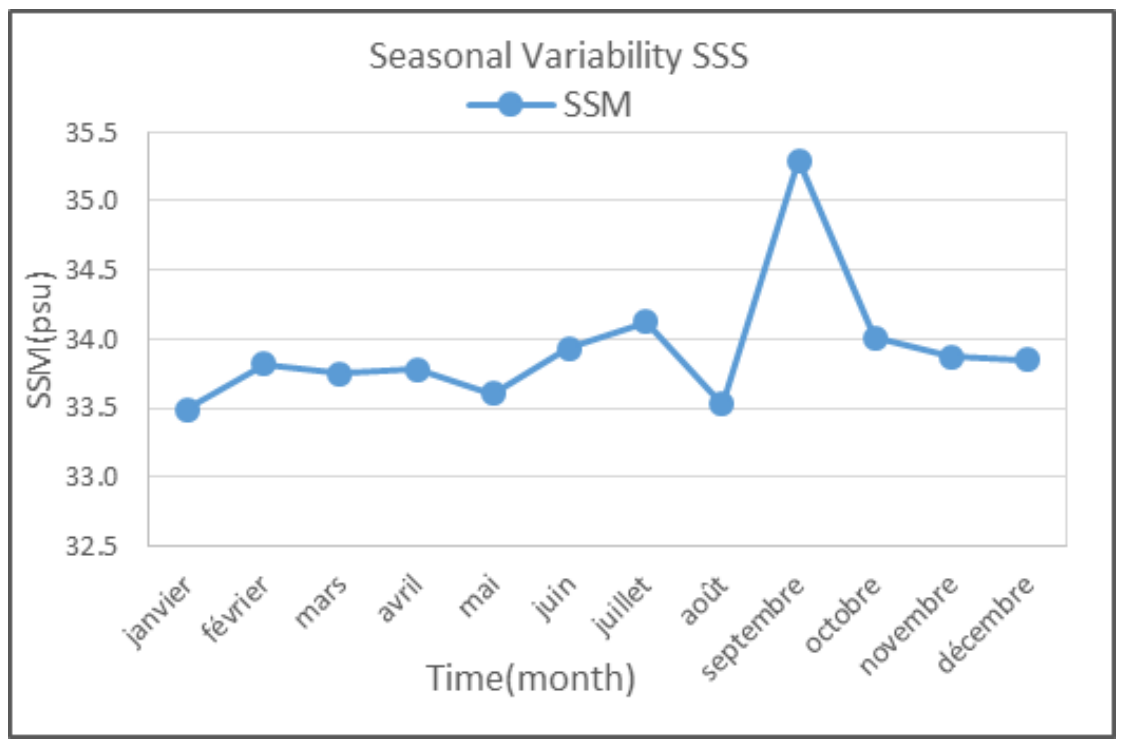

Fig 16: Seasonal variation of sea surface salinity from 2013 to 2018

3.3 Analysis of the relationships between oceanic parameters and tuna stocks

\subsubsection{Chlorophyll Concentration and Tuna Stocks}

Figure 17 shows the impact of the changes between the tuna catches recorded by the DAP (Direction de l'Aquaculture et de la Pêche) and the concentration of Chlorophyll_a in Ivorian waters and off the coast from 2013-2018. The analysis of tuna catches and chlorophyll_a concentration shows an almost proportionality between the two variables. When the Chlorophyll_a concentration is high, tuna stocks become as important and vice versa during the study period. It could therefore be said in general terms that the concentration of Chlorophyll_a influences the availability of tunas in the Ivorian ecosystem. Indeed, phytoplankton is the essential link in the food chain and the staple food of small fish (sardinella, balloon fish...)

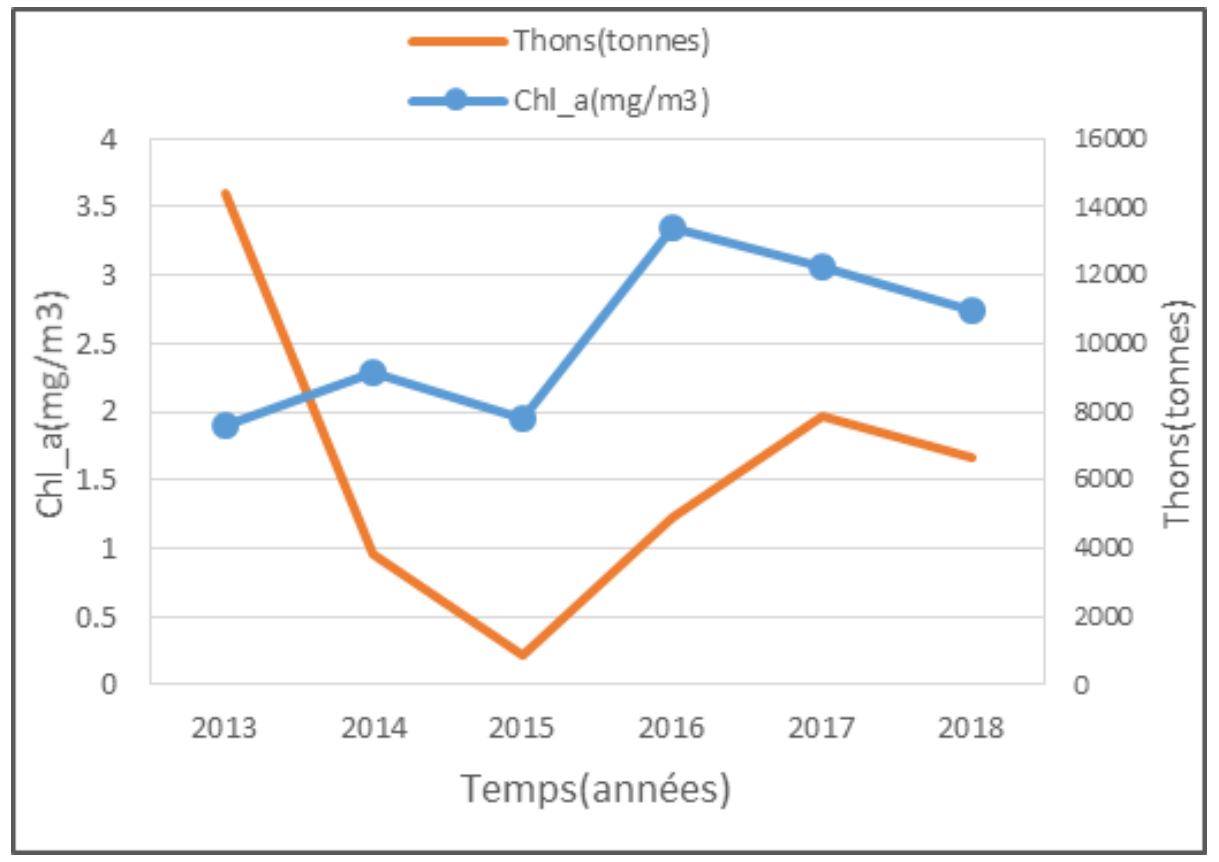

Fig 17: Relationship between Chlorophyll_a and Tuna catches

\subsubsection{Sea Surface Temperature and Tuna Stocks}

The analysis of tuna stocks and sea surface temperature generally shows a similar evolution between the two variables over the period of study. It is noted that the sea surface temperature is increasing simultaneously with the tuna stocks. Tuna are known to live in temperature ranges between 20 and
$30{ }^{\circ} \mathrm{C}$ and to reproduce in waters with Sea Surface Temperature above $26^{\circ} \mathrm{C}$. This hypothesis is perfectly reflected in Figure 18, which shows the evolution of tuna stocks in SSTs relatively greater than or equal to $27^{\circ} \mathrm{C}$. Therefore, a high sea temperature could guarantee a better availability of tunas in Sea Surface Temperature. 


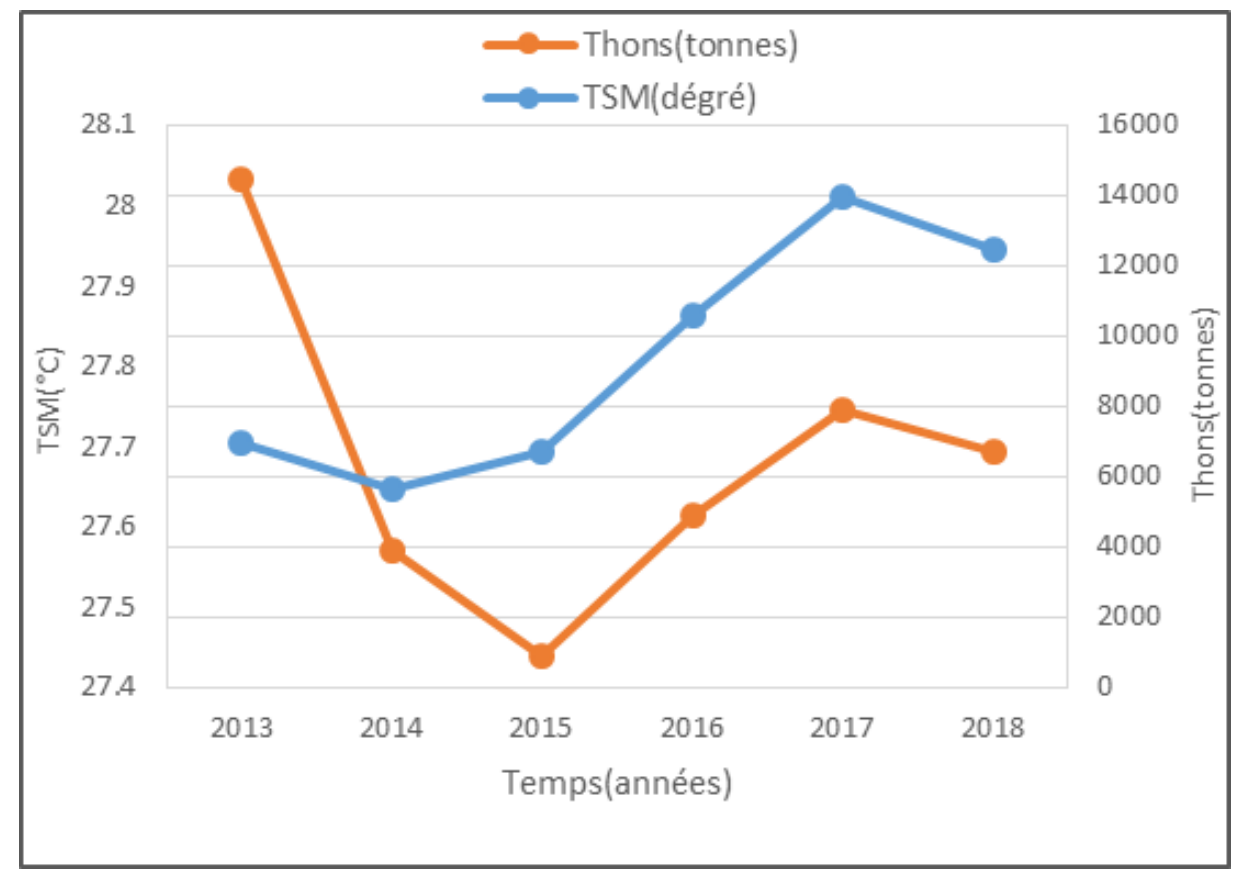

Fig 18: Relationship between Sea Surface Temperature and Tuna Catch

\subsubsection{Sea surface salinity and tuna stocks}

The observation of tuna catches and the annual variation in sea surface salinity reveals, in general, an inverse relationship between the two variables from 2013 to 2016 and a compliance in the evolution of the two variables from 2017 to 2018 (Fig. 19). From 2013 to 2016, there is an inverse evolution of the two variables. Tuna stocks decline over this period until reaching a minimum value of 896.3 tons in 2015 while sea surface salinity values increase from 2013 to 2015 before decreasing in 2016. Over the period 2017-2018, there is a perfect similarity in the evolution of the two variables. The low salinity values correspond to the low recruitment of tunas.

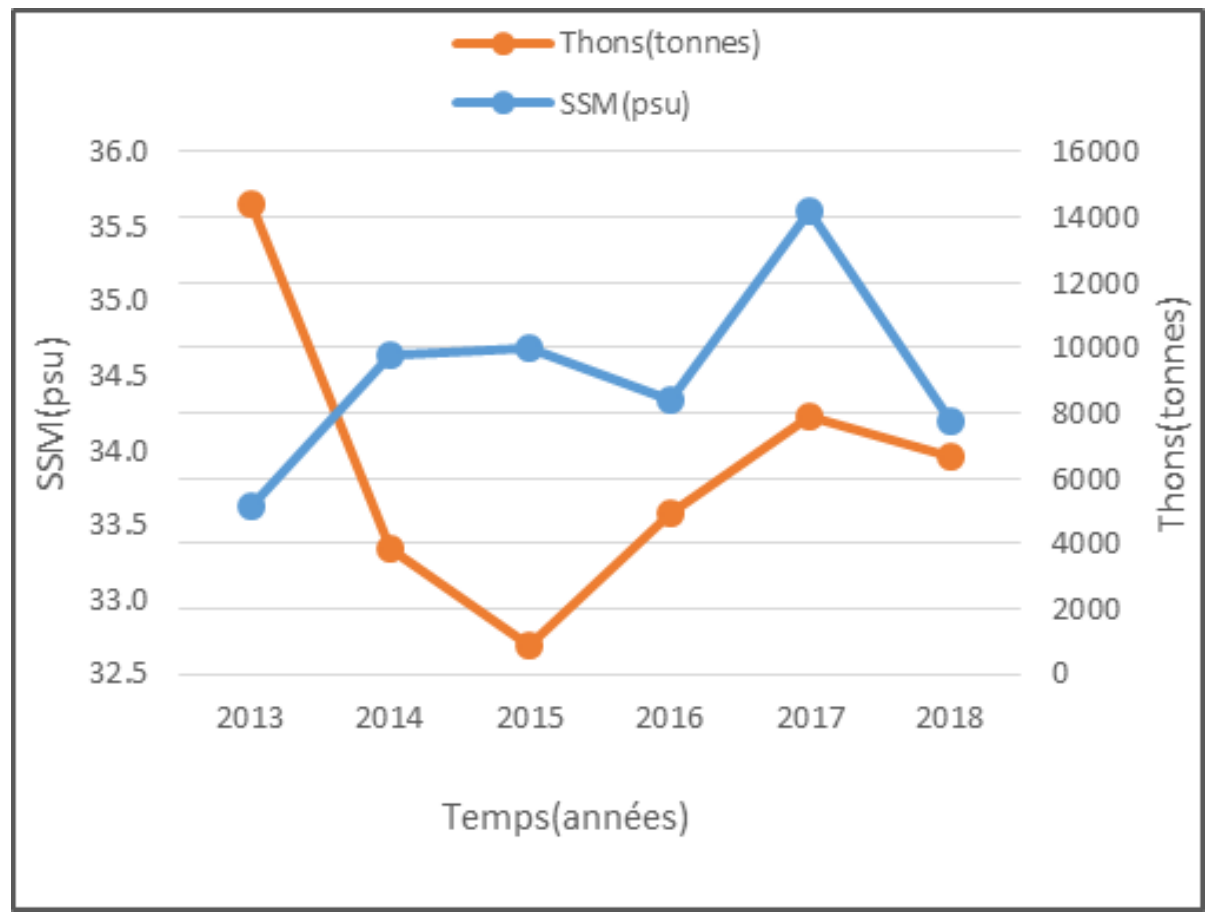

Fig 19: Relationship between Sea surface salinity and Tuna Catch

\subsubsection{Upwelling Index and Tunas}

The analysis in Figure 20 shows the inverse relationship between the upwelling index and tuna stocks. Low values of the upwelling index correspond to high catches of tunas and vice versa over the entire study period. Indeed, upwelling of cold water carries nutrients to the surface of the ocean and its occurrence contributes considerably to the availability of pelagic species. The low stocks of tunas associated with the high values of the upwelling index could be explained by the thermal preference of tropical tunas, they prefer warm waters. 


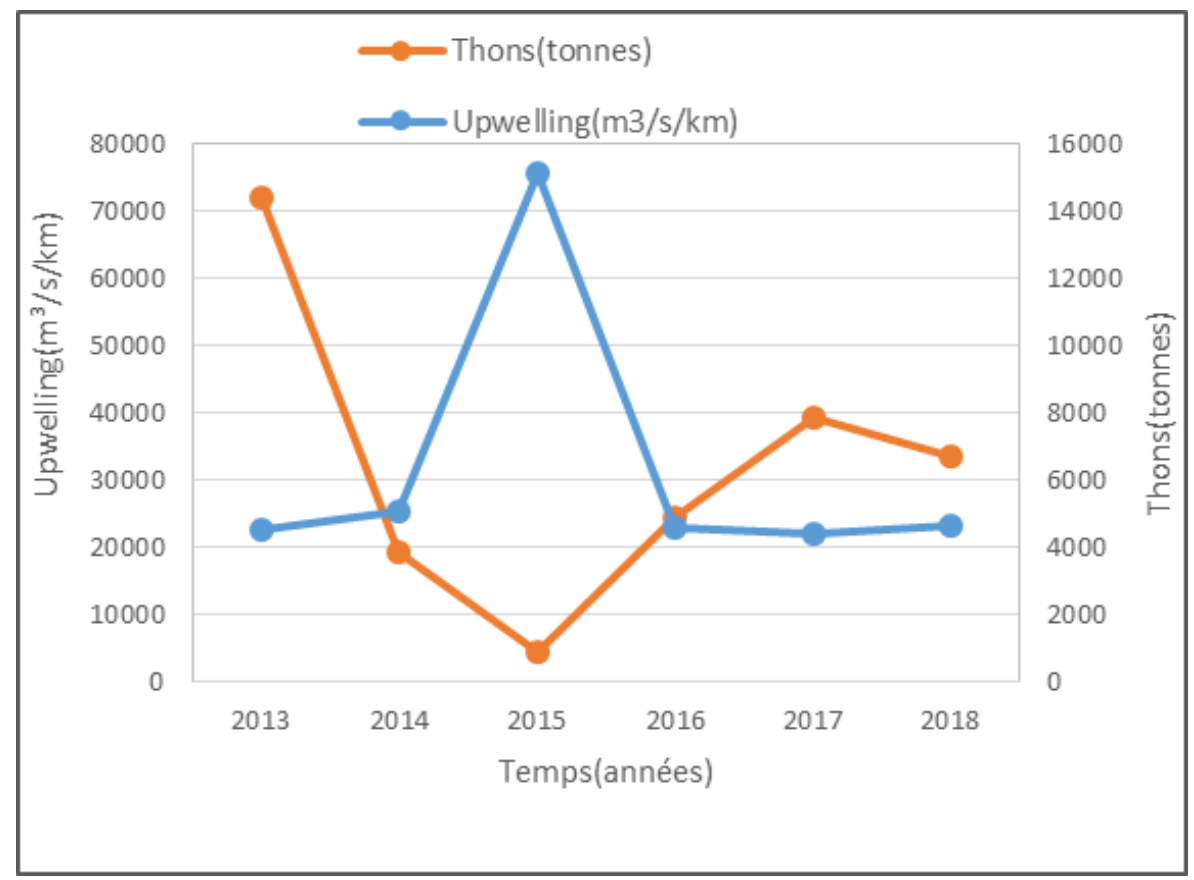

Fig 20: Relationship between Upwelling and Tuna catches

\subsubsection{Sea Turbulence and Tuna Stocks}

Figure 21 shows the relationship between the water column stability index (turbulence) and tuna stocks. Analysis of this figure shows an inverse relationship between the two variables from 2013 to 2018. In general, tuna catches decrease as turbulence values increase and vice versa over the study period. Indeed, the stability index of the water column has an important influence on the availability and distribution of pelagic species High turbulence corresponds to cloudy water where nutrients are less available. Waters of this nature correspond to areas less favorable to the availability of pelagic species.

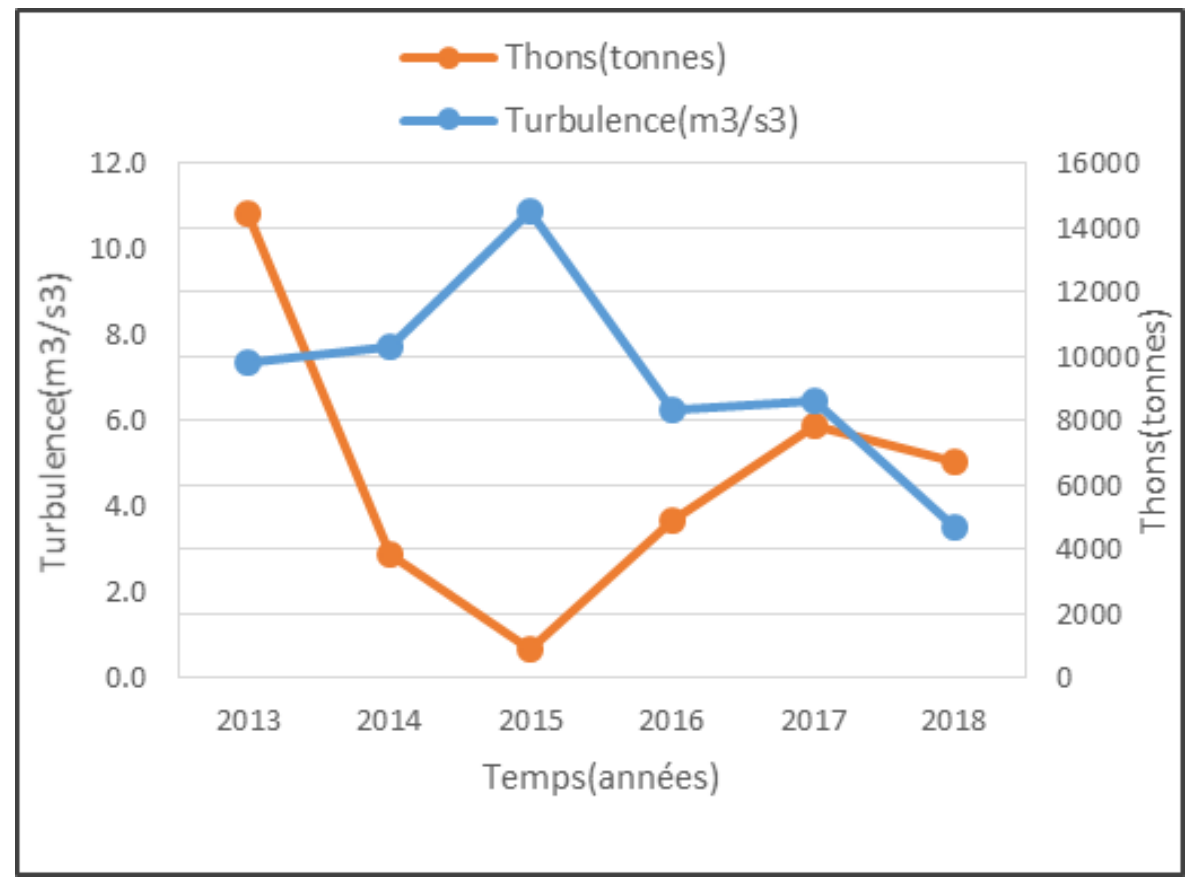

Fig 21: Relationship between Turbulence and Tuna Catch

\subsection{Discussion}

\section{Ocean Parameters and Tuna Recruitment}

\section{- Sea surface temperature}

The results of this study show that sea surface temperature plays an important role in the distribution of tunas relative to the thermal preference of tunas and also the areas favorable for their reproduction. (Travassos, 2001) [13] Designates waters with temperatures above $26^{\circ} \mathrm{C}$ as preferred spawning areas for Atlantic tunas.

\section{- The concentration of chlorophyll a}

In this study, it is noted that years of high catches of tunas coincide with high concentrations of Chlorophyll a, which indeed allow to estimate the amount of phytoplankton i.e. planktonic food. These results are in agreement with those of (Fonteneau, 1988) ${ }^{[14]}$ in his study on the introduction to tuna environmental problems in the Atlantic showed that an area rich in food under the ecological conditions favorable to the species is favorable to the availability of tunas. 


\section{- Sea surface salinity}

Sea surface salinity allows the characterization of water masses and, therefore, can be used in the discrimination of spawning areas of pelagic species. Our results concerning the spawning periods are consistent with (Cayré et al., 1988) [15] which states that the spawning period for tunas extends from the fourth quarter to the first quarter of the following year.

\section{- Turbulence and the upwelling index}

The upwelling phenomenon can be localized by the presence of cold sea water rich in phytoplankton. This fact is visible when the wind is at the origin of the upwelling, which also causes mixing (turbulence) that can be associated with less light availability in the surface layers Thus, it can become one of the factors limiting primary production (Jacques et Treguer, 1986) ${ }^{[16]}$. An increase in wind speed can also increase the speed of surface currents, which can drive phytoplankton-rich waters offshore. Changes in wind conditions can change the availability of food (phytoplankton) for larval fish and affect fish recruitment. These results are consistent with our findings that areas of high availability correspond to areas of low availability of tuna.

\section{General conclusion}

The main objective of this study conducted in Ivorian waters and the open ocean is to determine the optimal conditions for a good recruitment of tunas. To achieve this objective, the study of some oceanic parameters and their influences on the distribution of tunas was carried out using satellite imagery. The results revealed that:

- A high concentration of Chlorophyll leads to a good recruitment of tunas.

- A high sea temperature guarantees a better availability of tunas.

- The high values of sea turbulence (less stable water column) correspond to the lowest recruitment of tunas.

- The high values of the upwelling index correspond to the low recruitment of tuna.

- The low salinity values correspond to the low recruitment of tuna.

\section{References}

1. Sherman PW, Jarvis JUM, Alexander AD. The Biology of the Naked Mole-Rat. Princeton, New Jersey, Princeton Univ. Press 1991, 518.

2. Binet D. Influences des variations climatiques sur la pêcherie des Sardinella aurita ivoiro-ghanéenne: Relation sécheresse-surpêche. Oceanol. Acta 1982;5:443-452.

3. Chika NU, Chidi AI, Kenneth S. A sixteen-country mobilization for sustainable fisheries in the Guinea Current Large Marine Ecosystem. Ocean Coast. Manag 2006;49:385-412

4. Bakun A, Parrish HP. Turbulence, transport, and pelagic fish in the California and Peru Current systems. CalCOFI Rep. 1982;XXIII:99-112.

5. Bakun A, Roy C, Cury P. The comparative approach: Latitude dependence and effects of wind forcing on reproductive success. Sess. V SARP 1991;45:1-12.

6. Platt T, Fuentes-Yaco C, Frank K. Spring algal bloom and larval fish survival. Nature 2003;423:398-399.

7. Platt T, Sathyendranath S. Ecological indicators for the pelagic zone of the ocean from remote sensing. Remote Sens. Environ 2008;112:3426-3436.

8. Anoh KP, Pottier P. Géographie du littoral de Côte-
d'Ivoire : éléments de réflexion pour une politique de gestion intégrée. CNRS-LETG UMR 6554 et IGT: Nantes - Abidjan 2008, 325.

9. Bakun A, Parrish HP. Turbulence, transport, and pelagic fish in the California and Peru current systems. CalCOFI Rep 1973, 1982, XXIII:99-112.

10. Ekman W. On the influence of the Earth's rotation on ocean-currents, 1905, 1-51

11. Kassi AJB. Caractérisation et suivi des zones d'Upwelling pour la détermination des zones de rétention des espèces pélagiques dans le Golfe de Guinée à L'aide de la Télédétection et du Système d'Information Géographique : Cas de la Côte d'Ivoire. Ph.D. Thesis, Université Felix Houphouet-Boigny, Abidjan, Côte d'Ivoire 2012.

12. Travassos. La pêche du Thon Obèse (Thunnus Obesus) et les conditions hydroclimatiques dans l'océan Atlantique intertropical 2001.

13. Fonteneau A. Introduction aux problèmes des relations thons-environnement dans l'Atlantique. In: Beckett, J. (ed.) - Proceeding of the ICCAT Tuna Symposium, Part 1, Punta Delgada 1998, 275-317.

14. Cayré P, Amon Kothias JB, Stretta JM, Diouf T. Biologie des thons. In : Fonteneau, A. et J. Marcille (eds.), Ressources, pêche et biologie des thonidés tropicaux de l'Atlantique centre-est. FAO Document Technique sur les pêches 1988;292:157-268.

15. Jacques $G$, Treguer $P$. Les écosystèmes pélagiques marins. Masson, Paris, New York, Barcelone, Milan 1986, 243. 